\title{
METAIS PESADOS EM LATOSSOLO TRATADO COM LODO DE ESGOTO E EM PLANTAS DE CANA-DE-AÇÚCAR'
}

\author{
Fernando Carvalho Oliveira²; Maria Emilia Mattiazzo ${ }^{3 *}$ \\ ${ }^{2}$ Biossolo Agricultura e Ambiente S.C. Ltda., R. Edu Chaves, 822 - CEP: 13416-020 - Piracicaba, SP. \\ ${ }^{3}$ Depto. de Ciências Exatas - USP/ESALQ, C.P. 9 - CEP: 13418-900 - Piracicaba, SP. \\ *Autor correspondente <mmatiazo@carpa.ciagri.usp.br>
}

\begin{abstract}
RESUMO: A presença de metais pesados no lodo de esgoto constitui um dos maiores entraves para sua aplicação em solos agrícolas. Neste contexto, o presente trabalho teve como objetivos avaliar os efeitos de aplicações sucessivas de lodo de esgoto sobre o acúmulo de metais pesados num LATOSSOLO AMARELO Distrófico e em plantas de cana-de-açúcar e a fitodisponibilidade desses elementos através de extratores químicos. O experimento foi conduzido nos anos agrícolas 1996/97 e 1997/98 sendo que, no primeiro ano, além dos tratamentos calagem + adubação mineral e testemunha, foram aplicadas em área total, doses equivalentes a 33, 66 e $99 \mathrm{mg} \mathrm{ha}^{-1}$ (base seca) de lodo de esgoto. Em 1997/98 o lodo foi reaplicado em doses equivalentes a 37, 74 e $110 \mathrm{mg} \mathrm{ha}^{-1}$ (base seca). Foram detectados acúmulos de $\mathrm{Cu}, \mathrm{Cr}$, Ni e $\mathrm{Zn}$ na camada 0 - 0,2 m do solo. As concentrações de $\mathrm{Cd}$, $\mathrm{Cr}$, Ni e Pb nas amostras de plantas de cana-de-açúcar estiveram abaixo dos limites de determinação do método analítico empregado, porém, no caldo, a presença de $\mathrm{Cd}$, Cr e Ni, esteve abaixo de $0,02 \mathrm{mg} \mathrm{kg}^{-1}$. Os teores de Cu e Zn nas várias partes da cana-de-açúcar não foram superiores aos limites normais de variação encontrados na literatura. As soluções extratoras apresentaram eficiência apenas na avaliação da fitodisponibilidade do $\mathrm{Zn}$, determinado nas amostras de colmo e caldo, no ano agrícola 1997/98.
\end{abstract}

Palavras-chave: lodo de esgoto, metal pesado, extrator químico

\section{HEAVY METALS IN AN OXISOL TREATED WITH SEWAGE SLUDGE AND IN SUGARCANE PLANTS}

\begin{abstract}
The concern about the presence of heavy metals in plants growing in soils treated with sewage sludge can be a restricting factor for the use of this waste in agriculture. The aim of this paper was to evaluate the possibility of heavy metal accumulation in an acid soil after two successive sewage sludge applications and the availability, using chemical extractants for a typic hapludox, of these metals to sugarcane plants. The experiment was managed during two years, 1996/1997 and 1997/1998, and had 5 treatments in a randomized block design: lime + mineral fertilization, control and sewage sludge applied at three levels, 33, 66 and $99 \mathrm{mg}$ $\mathrm{ha}^{-1}$ in the first year and 37,74 and $110 \mathrm{mg} \mathrm{ha}^{-1}$ in the second year. After two sewage sludge applications in the two year period an increase of the level of $\mathrm{Cu}, \mathrm{Cr}, \mathrm{Ni}$ and $\mathrm{Zn}$ in the topsoil (0-0.2 m layer) was observed. Levels of $\mathrm{Cd}, \mathrm{Cr}, \mathrm{Ni}$ and $\mathrm{Pb}$ in plant leaves were bellow detection limits. In sugarcane juice the levels of $\mathrm{Cd}, \mathrm{Cr}$ and $\mathrm{Ni}$ were bellow $0.02 \mathrm{mg} \mathrm{kg}^{-1}$. Levels of $\mathrm{Cu}$ and $\mathrm{Zn}$ in leaves were not different from the usually reported values for plants cultivated in soils without sludge application. The chemical extractants used $\left(0.1 \mathrm{~mol} \mathrm{~L}^{-1} \mathrm{HCl}\right.$ and Mehlich-3) removed more $\mathrm{Cu}, \mathrm{Ni}$ and $\mathrm{Zn}$ from the soil than DTPA-TEA and all of them were effective only to preview $\mathrm{Zn}$ concentration in stalks and juice of ratton sugarcane.

Key words: sewage sludge, heavy metal, chemical extractant
\end{abstract}

\section{INTRODUÇÃO}

O acúmulo de metais pesados em solos agrícolas, devido à aplicações sucessivas de lodo de esgoto, é o aspecto que causa maior preocupação com relação a segurança ambiental necessária para a viabilização desta prática. Esses elementos podem expressar seu potencial poluente diretamente nos organismos do solo, pela disponibilidade às plantas em níveis fitotóxicos, além da possibilidade de transferência para a cadeia alimentar através das próprias plantas ou pela contaminação das águas de superfície e subsuperfície (Chang et al., 1987).

Embora ainda exista a necessidade de muitos estudos acerca deste assunto, a serem realizados por longo prazo e em condições de campo, Page et al. (1987) apontaram em trabalho de revisão, informações importantes sobre o comportamento, no sistema solo-planta, dos metais pesados adicionados via lodo. De acordo com os autores, dois aspectos são relevantes: o primeiro é que o lodo de esgoto desempenha, simultaneamente, papel de fonte e agente imobilizador dos metais pesados no solo; o segundo é que a absorção de metais pesados pelas plantas em função das taxas de aplicação do resíduo tem apresentado diferentes tipos de resposta incluindo comportamentos lineares, assintóticos, efeitos negativos ou simplesmente inexistentes.

Com base em observações referentes a absorção de metais pesados por diversas culturas,

\footnotetext{
${ }^{1}$ Parte da Tese de Doutorado do primeiro autor apresentada à USP/ESALQ - Piracicaba, SP.
} 
obtidas em experimentos de campo, Corey et al. (1987) perceberam que, na maioria dos casos, a absorção não aumentava linearmente com as taxas de aplicação de lodo de esgoto e sim, a partir de determinadas doses do resíduo, atingia e se estabelecia num valor máximo. Os autores denominaram este comportamento de "resposta platô", surgindo daí a chamada "teoria do platô" ou, do original, "plateau theory". De acordo com ela, a capacidade de adsorção específica dos metais pesados adicionados ao solo, via lodo de esgoto, persistirá enquanto esses elementos estiverem no solo, sugerindo, portanto, que os metais não permaneceriam em formas prontamente disponíveis às plantas e que o resíduo, que é a fonte de contaminação de metais pesados, tem em sua carga orgânica uma forma de aumentar a capacidade dos solos para retê-los. Neste sentido, após as concentrações de metais no tecido vegetal terem alcançado o chamado platô, em decorrência de sucessivas aplicações de lodo de esgoto, estas permanecerão nestes níveis até mesmo depois da interrupção das aplicações do resíduo (Chang et al., 1997; Logan et al., 1997).

A contaminação causada por metais pesados em solos tratados com resíduos urbanos é avaliada, freqüentemente, pelos teores totais desses elementos no solo. No entanto, no que se refere aos efeitos sobre as plantas e a cadeia alimentar, é necessário conhecimento das concentrações fitodisponíveis (Leschber et al., 1985).

Para avaliação da fitodisponibilidade vêm sendo estudados diversos extratores químicos, cuja eficiência é atribuída de acordo com o grau de correlação entre quantidades extraídas do solo e quantidades absorvidas pelas plantas (Kiekens \& Cottenie, 1985). Nesse sentido, os extratores químicos que mais têm se destacado são as soluções de ácidos, de substâncias quelantes e suas combinações (Singh \& Narwal, 1984; Dang et al., 1990; King \& Hajjar, 1990).

Todavia, existem grandes dificuldades para a definição de um extrator multielementar que inclua vários metais pesados e que ao mesmo tempo, seja eficiente para diagnosticar a sua disponibilidade às várias espécies vegetais cultivadas em vários tipos de solos. Além disso, em solos contaminados com metais pesados, principalmente quando a contaminação é devida a aplicação de resíduos orgânicos, a possibilidade da absorção desses elementos pelas plantas não se comportar linearmente com as quantidades de metais aplicadas ou presentes nos solos é mais um fenômeno natural a ser simulado por um extrator artificial, o que sem dúvida é outra dificuldade. Dessa forma, fica clara a necessidade de pesquisas nesta área do conhecimento, principalmente nas condições brasileiras, para as quais estudos desta natureza, em solos contaminados, são incipientes.

Este trabalho teve como objetivos avaliar os efeitos de aplicações sucessivas de lodo de esgoto sobre o acúmulo de metais pesados no solo, em amostras de folhas "+1", colmo e caldo de plantas de cana-de-açúcar, assim como a eficiência de diferentes extratores químicos em estimar a fitodisponibilidade desses elementos.

\section{MATERIAL E MÉTODOS}

O experimento foi conduzido nos anos agrícolas de 1996/97 e 1997/98, em condições de campo, numa área plana de LATOSSOLO AMARELO Distrófico selecionada na Estação Experimental do Instituto Agronômico de Campinas, em Piracicaba, SP. O clima, de acordo com a classificação de Köppen, é do tipo Cwa: subtropical com inverno seco (Setzer, 1966). Os parâmetros climáticos apresentam as seguintes médias anuais: precipitação, $1253 \mathrm{~mm}$; temperatura, $21,1^{\circ} \mathrm{C}$; umidade relativa do ar, $74 \%$; velocidade do vento, $2,2 \mathrm{~m} \mathrm{~s}^{-1}$. Algumas características químicas e físicas do solo são apresentadas na TABELA 1.

Foram empregadas duas remessas de lodo de esgoto anaeróbio semi-desidratado, obtidas junto à Estação de Tratamento de Esgotos de Barueri SABESP, Barueri, SP. A caracterização química parcial do resíduo (TABELA 2) foi realizada de acordo com Eaton et al. (1995).

Estabeleceram-se 5 tratamentos distribuídos num delineamento em blocos casualizados com 4 repetições, os quais foram aplicados em parcelas experimentais de $100 \mathrm{~m}^{2}$ cultivadas com cana-de-açúcar em ciclo anual. Os tratamentos foram: testemunha (T), calagem + adubação mineral (AM) e lodo de esgoto nas doses A (La), B (Lb) e C (Lc). O tratamento AM constou de calagem e adubação de plantio em 1996/97 e de adubação de cobertura na $1^{a}$ soqueira em 1997/98 (Spironello et al., 1996). A dose B (Lb) de lodo de esgoto foi definida em função da quantidade máxima de metais pesados possível de ser adicionada anualmente em solos agrícolas, conforme os critérios preconizados pela Norma 40 CFR (Code Federal Regulations) Part 503 da USEPA (1993), adotados pela CETESB (1999); a dose A (La) foi a metade e a dose C (LC), 1,5 vezes Lb. Desta forma, em base seca, as respectivas doses do resíduo foram: $1^{\text {a }}$ aplicação, 1996/97, 33 (A), 66 (B) e $99 \mathrm{mg} \mathrm{ha}^{-1}$ (C); $2^{a}$ aplicação, 1997/98, 37 (A), 74 (B) e $110 \mathrm{mg} \mathrm{ha}^{-1}$ (C). Os resíduos foram aplicados na superfície do solo em área total, com distribuição manual dentro das parcelas e incorporação, após um período de 7 dias de présecagem, na camada de $0-0,2 \mathrm{~m}$, com enxada rotativa. $\mathrm{Na}$ segunda aplicação a incorporação foi feita apenas nas entre-linhas da cultura. O plantio da cana-de-açúcar, variedade RB7851-48, foi realizado após 50 dias da incorporação do lodo de esgoto num espaçamento de 1,4 m entre-linhas.

Os teores totais dos metais pesados $\mathrm{Cd}, \mathrm{Cr}, \mathrm{Cu}$, $\mathrm{Ni}, \mathrm{Pb}$ e $\mathrm{Zn}$ foram avaliados no solo e nas plantas, ao final de cada ano agrícola. Para o solo, as avaliações foram realizadas em amostras coletadas, dentro da área 
TABELA 1 - Características químicas e físicas do LATOSSOLO AMARELO Distrófico antes da instalação do experimento.

\begin{tabular}{|c|c|c|c|c|c|c|c|c|c|c|c|}
\hline Prof. & $\begin{array}{c}\mathrm{pH} \\
\left(\mathrm{CaCl}_{2}\right)\end{array}$ & C-org & $P$ & K & $\mathrm{Ca}$ & $\mathrm{Mg}$ & $\mathrm{H}+\mathrm{Al}$ & Al & SB & $\mathrm{T}$ & $\mathrm{V}$ \\
\hline (m) & & $\mathrm{g} \mathrm{kg}^{-1}$ & $\mathrm{mg} \mathrm{dm}^{-3}$ & \multicolumn{7}{|c|}{ 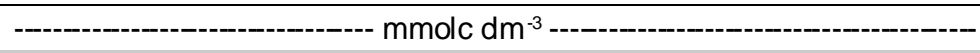 } & $\%$ \\
\hline $0-0,20$ & 4,1 & 9,29 & 3 & 0,3 & 11 & 5 & 47 & 10 & 16,3 & 63,3 & 27,7 \\
\hline $0,20-0,40$ & 4,1 & 8,13 & 2 & 0,3 & 14 & 5 & 47 & 10 & 19,3 & 66,3 & 29,1 \\
\hline $0,40-0,60$ & 4,1 & 6,38 & 1 & 0,1 & 11 & 3 & 47 & 12 & 14,1 & 61,1 & 23,1 \\
\hline Prof. & $\mathrm{Al}_{2} \mathrm{O}_{3}$ & $\mathrm{Fe}_{2} \mathrm{O}_{3}$ & $\mathrm{SiO}_{2}$ & \multicolumn{2}{|c|}{ Areia grossa } & Areia fina & \multicolumn{2}{|c|}{ Silte } & Argila & \multicolumn{2}{|c|}{ Densidade } \\
\hline$(\mathrm{m})$ & \multicolumn{3}{|c|}{ 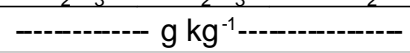 } & \multicolumn{6}{|c|}{ - } & \multicolumn{2}{|c|}{$\mathrm{kg} \mathrm{m}^{-3}$} \\
\hline $0-0,20$ & 108 & 71,5 & 121 & \multicolumn{2}{|c|}{195} & 329 & \multicolumn{2}{|c|}{141} & 335 & \multicolumn{2}{|c|}{1316} \\
\hline $0,20-0,40$ & 144 & 85,8 & 148 & \multicolumn{2}{|c|}{194} & 248 & \multicolumn{2}{|c|}{116} & 442 & \multicolumn{2}{|c|}{1292} \\
\hline $0,40-0,60$ & 150 & 88,7 & 155 & \multicolumn{2}{|c|}{211} & 218 & \multicolumn{2}{|c|}{90} & 481 & \multicolumn{2}{|c|}{1277} \\
\hline
\end{tabular}

TABELA 2 - Composição química parcial das duas remessas de lodo de esgoto utilizadas no experimento* (médias de 3 amostras compostas retiradas de cada remessa de lodo).

\begin{tabular}{lccc}
\hline \multirow{2}{*}{ Atributo } & & \multicolumn{2}{c}{ Lodo de esgoto } \\
\cline { 3 - 4 } & & 1996 & 1997 \\
\hline $\mathrm{pH}\left(\mathrm{H}_{2} \mathrm{O}, 1: 2,5\right)$ & & 12,25 & 8,50 \\
Carbono orgânico & $\left(\mathrm{g} \mathrm{kg}^{-1}\right)$ & 207,88 & 184,85 \\
N-total & $"$ & 25,58 & 21,71 \\
Relação C/N-total & & 8,13 & 8,51 \\
Cd-total & $\left(\mathrm{mg} \mathrm{kg}^{-1}\right)$ & 28,4 & 16,0 \\
Cr-total & $"$ & 385,0 & 386,0 \\
Cu-total & $"$ & 784,3 & 534,0 \\
Ni-total & $"$ & 238,6 & 286,0 \\
Pb-total & $"$ & 152,8 & 171,0 \\
Zn-total & $"$ & 1568,5 & 1649,0 \\
\hline
\end{tabular}

*Exceto o pH, cuja determinação foi feita a partir do material úmido, os demais resultados são expressos com base no material seco.

útil das parcelas $\left(25,2 \mathrm{~m}^{2}\right.$ centrais), na camada $0-0,2 \mathrm{~m}$, aos 360 dias após a incorporação do lodo de esgoto. Tais amostras foram compostas por 5 amostras simples retiradas nas entre-linhas da cultura. Os metais foram extraídos em "água-régia" $\left(\mathrm{HCl}+\mathrm{HNO}_{3}-3: 1\right)$ através de sistema de digestão em forno de microondas (CEM - modelo MDS-2000), conforme metodologia proposta por Nieuwenhuize et al. (1991). Foram utilizados $500 \mathrm{mg}$ de amostra, sendo o extrato recuperado em $50 \mathrm{~mL}$.

Nas plantas, as avaliações foram realizadas em amostras de folhas, colmos desfibrados e caldo. Por ocasião da colheita da cana-de-açúcar, na área útil das parcelas, foram coletadas 15 folhas " +1 ", identificadas com base no sistema de ordenação de Kuijper (Clements, 1980). Este material foi encaminhado para o laboratório, onde foi lavado seqüencialmente, com água destilada, solução $0,1 \mathrm{~mol} \mathrm{~L}^{-1}$ de $\mathrm{HCl}$ e água deionizada. Após a lavagem, selecionou-se o terço médio dessas folhas, retirou-se a nervura central e colocaram-se os limbos foliares para secar em estufa com circulação forçada de ar a $60^{\circ} \mathrm{C}$. Estes limbos foliares foram moídos e constituíram as amostras de folhas a serem analisadas.
Após a amostragem de folhas, foram coletados, aleatoriamente, 10 colmos por parcela, os quais, após lavagem, foram desfibrados mecanicamente. As amostras de colmos desfibrados foram secas e moídas da mesma forma que as amostras de folhas. Porções de colmos desfibrados, representativas de cada parcela experimental, foram encaminhadas para prensa para extração das amostras de caldo, que foram congeladas e analisadas oportunamente.

Nas amostras de plantas, os metais pesados foram determinados em extratos obtidos por digestão nítrico-perclórica. Para as amostras de folhas e colmos desfibrados, foram digeridos $2000 \mathrm{mg}$ do material com recuperação do extrato em volume final de $15 \mathrm{~mL}$. Para o caldo, foram digeridos $50 \mathrm{~mL}$ da amostra com recuperação do extrato em volume final de $10 \mathrm{~mL}$.

No estudo da fitodisponibilidade dos metais pesados foram avaliadas três soluções extratoras: solução $0,1 \mathrm{~mol} \mathrm{~L}^{-1}$ de $\mathrm{HCl}$, solução de Mehlich-3 e DTPA-TEA. A extração com $0,1 \mathrm{~mol} \mathrm{~L}^{-1}$ de $\mathrm{HCl}$ se fez agitando, por 30 minutos, $10,00 \mathrm{~g}$ de solo com $50 \mathrm{~mL}$ de solução (Reed \& Martens, 1996). A solução de Mehlich-3 foi empregada na proporção de $50 \mathrm{~mL}$ para $5,00 \mathrm{~g}$ de solo, agitando-se 5 minutos (Mehlich, 1984). A extração com DTPA-TEA consistiu em agitar $25,00 \mathrm{~g}$ de solo com 50 $\mathrm{mL}$ de solução extratora, por 2 horas (Lindsay \& Norvell, 1978). Em todos os métodos, após a agitação, os extratos foram filtrados através de processos de filtração lenta.

As determinações analíticas dos metais pesados nos extratos de solo e plantas foram feitas por espectrometria de absorção atômica convencional com chama ar/acetileno.

Os teores de metais pesados determinados no solo foram testados, para os tratamentos $\mathrm{T}$, La, Lb e Lc, por modelos de regressão polinomial de $1^{\circ}$ e $2^{\circ}$ grau. As concentrações de metais pesados nas amostras de plantas foram relacionadas, para todos os tratamentos, dentro de cada ano agrícola, com os teores totais de metais extraídos do solo. Aos dados foram testados modelos de regressão polinomial de $1^{\circ}$ e $2^{\circ}$ grau e um modelo exponencial modificado a partir da chamada equação do platô proposta por Logan \& Chaney (1987). 
Este último pressupõe uma resposta do tipo assintótica para a absorção de metais pesados em função de seu acúmulo no solo. A descrição do modelo é a seguinte:

$$
y=A\left(1-e^{-B x}\right)
$$

na qual y é a concentração do metal na amostra de planta $\left(\mathrm{mg} \mathrm{kg}^{-1}\right)$, x é o teor total do metal recuperado do solo $\left(\mathrm{mg} \mathrm{kg}^{-1}\right)$, A é a concentração assintótica (platô) do metal na amostra de planta, B é a constante que define as alterações nos teores de metais da amostra em função do acréscimo do metal no solo. Quando todos os modelos foram significativos, optou-se pelo modelo exponencial, desde que ele apresentasse coeficiente de determinação igual ou maior que o dos modelos de regressão polinomial.

A eficiência dos extratores químicos na predição da disponibilidade de metais pesados às plantas foi avaliada através da análise de correlação linear simples entre os teores determinados nas amostras de planta e os teores removidos do solo pelos extratores utilizados.

\section{RESULTADOS E DISCUSSÃO}

\section{Acúmulo de metais pesados no solo}

A aplicação de lodo de esgoto proporcionou, nos dois anos agrícolas, aumentos lineares nos teores totais de $\mathrm{Cu}, \mathrm{Cr}$ e $\mathrm{Zn}$ (TABELA 3). O Ni foi detectado somente em 1997/98, nas doses Lb e Lc. Os metais Cu e $\mathrm{Zn}$ foram os que apresentaram os maiores teores acumulados no solo, o que se explica pelas suas concentrações no resíduo. Para o $\mathrm{Cu}$, ao final do segundo ano agrícola, foram observados acréscimos médios, em relação à testemunha, variando de $\mathrm{La}$ para Lc, de 55 a $154 \%$, e no caso do $\mathrm{Zn}$, de 148 a $381 \%$.

Cádmio e Pb apresentaram-se em concentrações abaixo do limite de determinação do método analítico empregado. No entanto, isto não significa que eles estivessem ausentes e sim que suas concentrações no solo foram respectivamente, menores que 8 e $76 \mathrm{mg} \mathrm{kg}^{-1}$. Situação semelhante foi observada para o $\mathrm{Ni}$ em todas as doses aplicadas em 1996/97 e na menor dose aplicada em 1997/98, ou seja, as concentrações estavam abaixo de $10 \mathrm{mg} \mathrm{kg}^{-1}$. De fato, quando são consideradas as quantidades $\left(\mathrm{mg} \mathrm{kg}^{-1}\right)$ de metais aplicadas ao solo via lodo de esgoto (TABELA 4), tomando-se por base Lc e as duas aplicações feitas, ter-se-ia um acúmulo máximo de $\mathrm{Cd}, \mathrm{Pb}$ e $\mathrm{Ni}$ de respectivamente, 1,74, 12,91 e $8,97 \mathrm{mg} \mathrm{kg}^{-1}$, o que está abaixo dos limites de determinação.

O potencial de acúmulo de metais pesados em solos, devido a disposição de lodo de esgoto, vem sendo exaustivamente apontado nos EUA desde a década de 70 (King \& Morris, 1972; Cunningham et al., 1975; Baxter et al., 1983). No Brasil, este potencial foi verificado por Silva (1995), Marques (1996), Anjos (1999) entre outros.
Os teores de $\mathrm{Cu}, \mathrm{Cr}$, Ni e $\mathrm{Zn}$ presentes no solo podem ser maiores do que aqueles removidos pelo extrator "água régia". Considerando-se o somatório dos teores nativos dos metais extraídos pela "água régia" e as aplicações acumuladas desses mesmos metais pesados via lodo de esgoto (TABELA 4), observa-se que os teores recuperados nos tratamentos com lodo de esgoto foram predominantemente inferiores, o que pode ser atribuído a problemas na amostragem do solo, que refletiria a heterogeneidade na incorporação do lodo, ao método de extração que nem sempre apresenta 100\% de eficiência (Keller \& Védy, 1994) e à possibilidade desses elementos estarem sendo lixiviados para camadas abaixo de 0,2 $\mathrm{m}$.

A comparação dos teores totais determinados em 1996/97 com aqueles de 1997/98 (TABELA 3) evidencia que aplicações sucessivas de lodo de esgoto certamente levarão a um acúmulo desses metais na camada superficial do solo. Considerando-se os teores críticos de metais pesados em solos preconizados pelas Diretrizes da Comunidade Européia (Hall, 1998) e tendo como base os teores médios teóricos dos vários metais incrementados no solo através do lodo de esgoto utilizado (TABELA 4), estima-se que o Cd seria o primeiro elemento a atingir o limite crítico $\left(3 \mathrm{mg} \mathrm{kg}^{-1}\right)$, o que levaria de 3 a 10 anos no caso de aplicações anuais e sucessivas de doses médias variando, respectivamente, entre 105 e $35 \mathrm{mg} \mathrm{ha}^{-1}$ (base seca). De acordo com os critérios da USEPA (40 CFR Part 503) (Hall, 1998), estima-se que o $\mathrm{Ni}$ seria o primeiro metal a atingir o limite crítico (230 mg kg-1), o que levaria de 22 a 66 anos para as mesmas taxas e freqüência de aplicações citadas anteriormente.

Dessa forma, observa-se que, mesmo com elevadas taxas de aplicação, quando são considerados apenas os aspectos relacionados com metais pesados, as normas da USEPA (1993) são relativamente permissíveis. No entanto, cabe lembrar que estas normas têm sido alvo de críticas contundentes por parte de alguns autores. Wallace \& Wallace (1994) e McBride (1995) chamaram a atenção para vários fatores que não foram considerados pela USEPA na elaboração das normas. Destacaram, entre outros, aspectos relacionados com a possibilidade de interação fitotóxica entre os metais pesados, a falta de pesquisas a longo prazo que comprovem a segurança dos limites estabelecidos e o desconhecimento do destino desses elementos no solo após os limites de acúmulo serem alcançados.

\section{Acúmulo de metais pesados nas plantas}

Com relação a possibilidade de incrementos na absorção de $\mathrm{Cd}, \mathrm{Cr}, \mathrm{Ni}$ e $\mathrm{Pb}$ pelas plantas de cana-de-açúcar, não foram possíveis maiores considerações tendo em vista que suas concentrações, em todas as amostras analisadas, estiveram abaixo do limite de determinação do método analítico utilizado. Contudo, é possível assegurar que, caso tenha ocorrido 
TABELA 3 - Teores totais de $\mathrm{Cu}$, Cr, Ni e Zn do solo, na camada 0 - 0,2 m, nos anos agrícolas 1996/97 e 1997/98.

\begin{tabular}{|c|c|c|c|c|c|c|}
\hline \multirow[t]{2}{*}{ Ano agrícola } & \multicolumn{4}{|c|}{ Dose de lodo de esgoto $\left(\mathrm{mg} \mathrm{ha}^{-1}\right)$} & \multicolumn{2}{|c|}{ Termo de Regressão $\left(R^{2}\right)$} \\
\hline & 0 & $33(37)$ & $66(74)$ & $99(110)$ & Linear & Quadrático \\
\hline & \multicolumn{6}{|c|}{ - Cobre $\left(\mathrm{mg} \mathrm{kg}^{-1}\right)$ - } \\
\hline 1996/97 & 17,86 & 19,47 & 27,90 & 30,97 & $0,93^{* *}$ & ns \\
\hline \multirow[t]{2}{*}{ 1997/98 } & 16,87 & 26,17 & 36,39 & 42,85 & $0,99^{\star \star}$ & ns \\
\hline & \multicolumn{6}{|c|}{ - Cromo $\left(\mathrm{mg} \mathrm{kg}^{-1}\right)$ - } \\
\hline 1996/97 & 16,57 & 21,56 & 25,30 & 25,59 & $0,89^{\star \star}$ & ns \\
\hline \multirow{2}{*}{ 1997/98 } & 15,55 & 18,14 & 25,21 & 27,19 & $0,95^{\star \star}$ & ns \\
\hline & \multicolumn{6}{|c|}{ - } \\
\hline 1996/97 & n.d. ${ }^{2}$ & n.d. & n.d. & n.d. & - & - \\
\hline \multirow[t]{2}{*}{$1997 / 98$} & n.d. & n.d. & 10,65 & 14,63 & - & - \\
\hline & \multicolumn{6}{|c|}{ - } \\
\hline 1996/97 & 21,14 & 39,22 & 40,41 & 41,27 & $0,68^{\star \star}$ & $0,95^{\star \star}$ \\
\hline $1997 / 98$ & 20,19 & 50,03 & 77,11 & 97,21 & $0,99^{\star \star}$ & ns \\
\hline
\end{tabular}

${ }^{1}$ Doses entre parênteses referem-se ao ano agrícola 1997/98; ${ }^{2}$ n.d. - não detectado, valor abaixo do limite de determinação do método analítico; **, ns Indicam respectivamente, que os termos de regressão linear ou quadrática foram significativos a $P \leq 0,01$ ou não significativo pelo teste $\mathrm{F}$.

TABELA 4 - Quantidades de metais pesados adicionadas ao solo $\left(\mathrm{mg} \mathrm{kg}^{-1}\right)$, na camada de 0 - 0,2 $\mathrm{m}$, pela aplicação de lodo de esgoto nos anos agrícolas 1996/97 e 1997/98 e valores acumulados no período'.

\begin{tabular}{|c|c|c|c|c|c|c|c|c|c|}
\hline \multirow{3}{*}{ Metal } & \multicolumn{9}{|c|}{ Dose de lodo de esgoto $\left(\mathrm{mg} \mathrm{ha}^{-1}\right)$} \\
\hline & \multicolumn{3}{|c|}{ Ano agrícola 1996/97 } & \multicolumn{3}{|c|}{ Ano agrícola 1997/98 } & \multicolumn{3}{|c|}{ Valor acumulado } \\
\hline & 33 & 66 & 99 & 37 & 74 & 110 & 70 & 140 & 209 \\
\hline Cádmio & 0,36 & 0,71 & 1,07 & 0,22 & 0,45 & 0,67 & 0,58 & 1,16 & 1,74 \\
\hline Cobre & 9,83 & 19,67 & 29,50 & 7,51 & 15,01 & 22,52 & 17,34 & 34,68 & 52,02 \\
\hline Cromo & 4,83 & 9,65 & 14,48 & 5,43 & 10,85 & 16,13 & 10,26 & 20,50 & 30,61 \\
\hline Níquel & 2,99 & 5,98 & 8,97 & 4,02 & 8,04 & 11,95 & 7,01 & 14,02 & 20,92 \\
\hline Chumbo & 1,92 & 3,84 & 5,76 & 2,40 & 4,81 & 7,15 & 4,32 & 8,65 & 12,91 \\
\hline Zinco & 19,67 & 39,34 & 59,01 & 23,18 & 46,36 & 69,92 & 42,85 & 85,70 & 128,93 \\
\hline
\end{tabular}

${ }^{1}$ Valores calculados com base no teor do metal presente no resíduo, com a dose aplicada e considerando a camada de incorporação no solo (0-0,2 m) cuja densidade de $1316 \mathrm{~kg} \mathrm{~m}^{-3}$ foi determinada por Marciano (1999).

absorção, as concentrações ficariam abaixo de: amostras de folhas e colmo desfibrado - $\mathrm{Cd}<0,60$ $\mathrm{mg} \mathrm{kg}^{-1}, \mathrm{Cr}$ e $\mathrm{Ni}<0,75 \mathrm{mg} \mathrm{kg}^{-1}, \mathrm{~Pb}<5,70 \mathrm{mg} \mathrm{kg}^{-1}$; amostras de caldo - $\mathrm{Cd}, \mathrm{Cr}$ e $\mathrm{Ni}<0,02 \mathrm{mg} \mathrm{kg}^{-1}$, $\mathrm{Pb}<0,15 \mathrm{mg} \mathrm{kg}^{-1}$.

Os menores limites obtidos para determinação desses metais nas amostras de caldo foram devidos a possibilidade de concentração do extrato da amostra. Tais limites sugerem que praticamente não ocorreram efeitos das doses de lodo de esgoto sobre as concentrações dos metais no caldo da cana-de-açúcar. Estes resultados são de grande relevância já que, não sendo verificados efeitos tóxicos às plantas, o caldo é o produto industrial da cana-de-açúcar, no qual o acúmulo de metais pesados poderia causar problemas a curto prazo.

Resultados de pesquisa obtidos no Brasil com a cultura da cana-de-açúcar não apontaram acréscimos na concentração desses metais pesados nas amostras da planta. Deve-se ressaltar porém, que a maioria das doses de lodo de esgoto empregadas pelos autores foram menores que as utilizadas no presente trabalho, além de terem sido aplicadas apenas por um ano agrícola. Silva (1995) verificou concentrações traços de $\mathrm{Cd}, \mathrm{Cr}$, Ni e Pb em amostras de colmos + folhas e de colmos de plantas cultivadas em áreas tratadas com lodo de esgoto (0, 20 e $40 \mathrm{mg} \mathrm{ha}^{-1} \mathrm{com} 62 \%$ de umidade) porém, foi categórico em afirmar que os tratamentos não conferiram efeito sobre as variáveis em questão. De acordo com o autor, as baixas concentrações encontradas nas amostras poderiam ser devidas a um mecanismo qualquer de retenção desses metais nas raízes das plantas ou até mesmo por um possível antagonismo desses elementos com cátions divalentes, como $\mathrm{Ca}^{2+}, \mathrm{Mn}^{2+}$ e $\mathrm{Zn}^{2+}$, presentes em maiores quantidades no solo. Marques (1996) também não detectou a presença de $\mathrm{Cd}, \mathrm{Cr}$ e $\mathrm{Pb}$ em amostras de folhas, colmo e caldo de plantas cultivadas com a utilização de até $160 \mathrm{mg} \mathrm{ha}^{-1}$ (com $74 \%$ de umidade).

Os teores de $\mathrm{Cu}$ variaram, entre as amostras analisadas em todos tratamentos, para os anos 1996/97 e 1997/98, respectivamente entre: folha - 5,04 a 6,65 $\mathrm{mg} \mathrm{kg}^{-1}, 4,59$ a $6,09 \mathrm{mg} \mathrm{kg}^{-1}$; colmo - 2,20 a $3,54 \mathrm{mg} \mathrm{kg}^{-1}$, 1,94 a $2,95 \mathrm{mg} \mathrm{kg}^{-1}$; caldo - 0,25 a $0,60 \mathrm{mg} \mathrm{kg}^{-1}$, 0,41 a $0,88 \mathrm{mg} \mathrm{kg}^{-1}$. Para o $\mathrm{Zn}$ os intervalos de variação 
encontrados foram: folha $-13,58$ a $21,10 \mathrm{mg} \mathrm{kg}^{-1}, 13,40$ a $21,00 \mathrm{mg} \mathrm{kg}^{-1}$; colmo $-4,16$ a $8,46 \mathrm{mg} \mathrm{kg}^{-1}, 5,23$ a $9,58 \mathrm{mg} \mathrm{kg}^{-1}$; caldo - 0,56 a 1,14 $\mathrm{mg} \mathrm{kg}^{-1}, 1,05 \mathrm{a}$ $1,41 \mathrm{mg} \mathrm{kg}^{-1}$.

De acordo com Sobral \& Weber (1983), os teores de micronutrientes nas partes das plantas de cana-de-açúcar variam em função da variedade, de "cana-planta" para "cana-soca", com a idade das plantas e com o tipo de solo onde são cultivadas. No entanto, considerando apenas como uma referência os dados apresentados para teores de $\mathrm{Cu}$ (Orlando Filho et al., 1980a) e de Zn (Orlando Filho et al., 1980b), obtidos para a variedade CB41-76, cultivada em diversos tipos de solo e avaliada em várias idades, pode-se afirmar que os teores obtidos no presente trabalho, nos colmos e na folha " +1 ", ocorreram dentro das variações encontradas por estes autores.

Na Figura 1, observa-se no ano agrícola 1996/ 97, aumentos dos teores de Cu na folha "+1" em função dos acréscimos nos teores totais do solo. Nesta relação, o modelo matemático que melhor se ajustou foi 0 exponencial, sugerindo uma concentração platô de $\mathrm{Cu}$ de $6,96 \mathrm{mg} \mathrm{kg}^{-1}$ em média, $1,68 \mathrm{mg} \mathrm{kg}^{-1}$ acima dos teores obtidos para as folhas dos tratamentos sem lodo de esgoto (tratamentos AM e T). Para as amostras de colmo e caldo, não houve evidencias de efeitos dos tratamentos com lodo de esgoto.

Nas amostras relativas a primeira soqueira, ano agrícola 1997/98, foram verificados efeitos significativos em todos os casos. Nas folhas observou-se novamente um comportamento assintótico em relação aos acréscimos nos teores de $\mathrm{Cu}$ do solo. Enquanto esses teores variaram nos tratamentos com lodo de esgoto entre 25 e $50 \mathrm{mg} \mathrm{kg}^{-1}$, as folhas apresentaram uma concentração platô estimada em $5,79 \mathrm{mg} \mathrm{kg}^{-1}, 1,04 \mathrm{mg} \mathrm{kg}^{-1}$ em média, acima dos teores obtidos para as amostras dos tratamentos AM e T. Comportamento semelhante é observado nas amostras de colmo, as quais apresentaram para a mesma variação de Cu no solo, uma concentração platô de $2,80 \mathrm{mg} \mathrm{kg}^{-1}$, em média $0,64 \mathrm{mg} \mathrm{kg}^{-1}$ maior do que os tratamentos AM e T. Nas amostras de caldo, o comportamento observado foi quadrático.

Com relação ao Zn, observa-se na Figura 2, para o ano agrícola 1996/97, efeitos significativos sobre os teores na folha " 1 " e no colmo, em função do acréscimo verificado nos teores totais do solo. Para as amostras de folha observa-se uma concentração platô estimada em $19,97 \mathrm{mg} \mathrm{kg}^{-1}$, cerca de $4,10 \mathrm{mg} \mathrm{kg}^{-1}$ de acréscimo em relação aos teores verificados nos tratamentos AM e T. Os teores no colmo aumentaram linearmente com os teores do solo e no caldo não foram verificados efeitos significativos.

Em 1997/98 foi observado um comportamento assintótico para os teores de $\mathrm{Zn}$ na folha e no caldo. As folhas "+1" apresentaram concentração platô de 19,71 $\mathrm{mg} \mathrm{kg}^{-1}$, o que representa um acréscimo médio de 5,27 $\mathrm{mg} \mathrm{kg}^{-1}$ em relação aos tratamentos sem lodo de esgoto.
No caldo a concentração platô foi estimada em 1,35 $\mathrm{mg} \mathrm{kg}^{-1}$, cerca de $0,20 \mathrm{mg} \mathrm{kg}^{-1}$ maior em relação a $\mathrm{AM} \mathrm{e}$ T. Os teores de $\mathrm{Zn}$ nas amostras de colmo aumentaram linearmente com o acréscimo nos teores totais do elemento no solo.

A absorção de $\mathrm{Cu}$ e $\mathrm{Zn}$ por plantas cultivadas em solos tratados com lodo de esgoto, caracterizando respostas do tipo platô, também foi encontrada em estudos de longo prazo realizados por Barbarick et al. (1995) com a cultura do trigo e por Logan et al. (1997), com a cultura do milho. Marques (1996), num trabalho conduzido por apenas 1 ano, observou que a aplicação de até $160 \mathrm{mg} \mathrm{ha}^{-1}$ (com $74 \%$ de umidade) de lodo de esgoto não alterou, quando comparado com a testemunha, as concentrações de $\mathrm{Cu}$ e Zn em amostras de colmo e caldo de cana-de-açúcar (var. SP 70-1143).

Os incrementos nos teores de $\mathrm{Cu}$ e $\mathrm{Zn}$ verificados em algumas amostras de plantas não foram, de maneira geral, proporcionais aos aumentos que houve nos teores totais desses metais, no solo. Dessa forma, nos casos em que foram observados comportamentos assintóticos é possível que seja um indicativo de que a partir de determinados teores acumulados no solo os teores absorvidos pelas plantas atinjam e se estabeleçam num valor máximo. Esta possibilidade é defendida pela chamada "teoria do platô" proposta por Corey et al. (1987).

No presente trabalho não foi objetivo comprovar ou não a citada teoria, mesmo porque a forma e o tempo pelos quais foi conduzido o experimento não foram adequados para isso. Além disso, os teores de Corgânico nos solos tratados com lodo de esgoto mantiveram-se elevados em relação a $T$ e os valores de pH apresentaram-se próximos a 7,0 (Oliveira, 2000). Para Logan et al. (1997) estas variáveis são os principais fatores de confundimento da teoria. De acordo com McBride (1995) e Chang et al. (1997), após o cessamento das aplicações de lodo de esgoto, com os processos de degradação do C-orgânico e a acidificação natural do solo, os metais pesados ora indisponíveis, passariam a formas solúveis e disponíveis às plantas. Esta é, de forma simplificada, uma definição da chamada "teoria da bomba relógio", proposta por McBride (1995).

Essas teorias ainda são objetos de estudo, de forma que não existe um consenso a este respeito. É fato que os destinos desses elementos, após a paralisação das aplicações do resíduo, são questões em aberto. É necessária a continuidade do estudo para verificar se as tendências observadas nos anos agrícolas 1996/97 e 1997/98 são válidas a longo prazo. É recomendável portanto, cautela na disposição desses resíduos no solo, e que ela seja sempre acompanhada de monitoramento do sistema solo-planta-água, até que mais trabalhos de pesquisa, conduzidos a longo prazo, permitam definir parâmetros e uma sistemática de aplicação comprovadamente adequada para as condições dos trópicos. 
Avaliação da fitodisponibilidade de metais pesados

As quantidades de $\mathrm{Cd}, \mathrm{Cr}$ e $\mathrm{Pb}$ eventualmente removidas do solo pelas soluções de DTPA-TEA, $\mathrm{HCl} 0,1$ mol L-1 e Mehlich-3 estiveram, nos dois anos agrícolas, abaixo do limite de determinação do método analítico empregado. Dessa forma, para o extrator DTPA-TEA as quantidades desses metais nas amostras de solo foram respectivamente, $<0,16,<0,2 \mathrm{e}<1,5 \mathrm{mg} \mathrm{kg}^{-1}$. Para a solução de $\mathrm{HCl} 0,1 \mathrm{~mol} \mathrm{~L}^{-1}$ tais quantidades foram $<0,4$, $<0,5 \mathrm{e}<3,8 \mathrm{mg} \mathrm{kg}^{-1}$ ao passo que, para Mehlich-3 as quantidades foram $<0,8,<1,0 \mathrm{e}<7,6 \mathrm{mg} \mathrm{kg}^{-1}$. Estas observações somadas a não detecção dos referidos metais pesados nas amostras de plantas, ilustram as limitações do método analítico empregado não permitindo portanto, maiores considerações sobre esses elementos.

Ano agrícola 1996/97
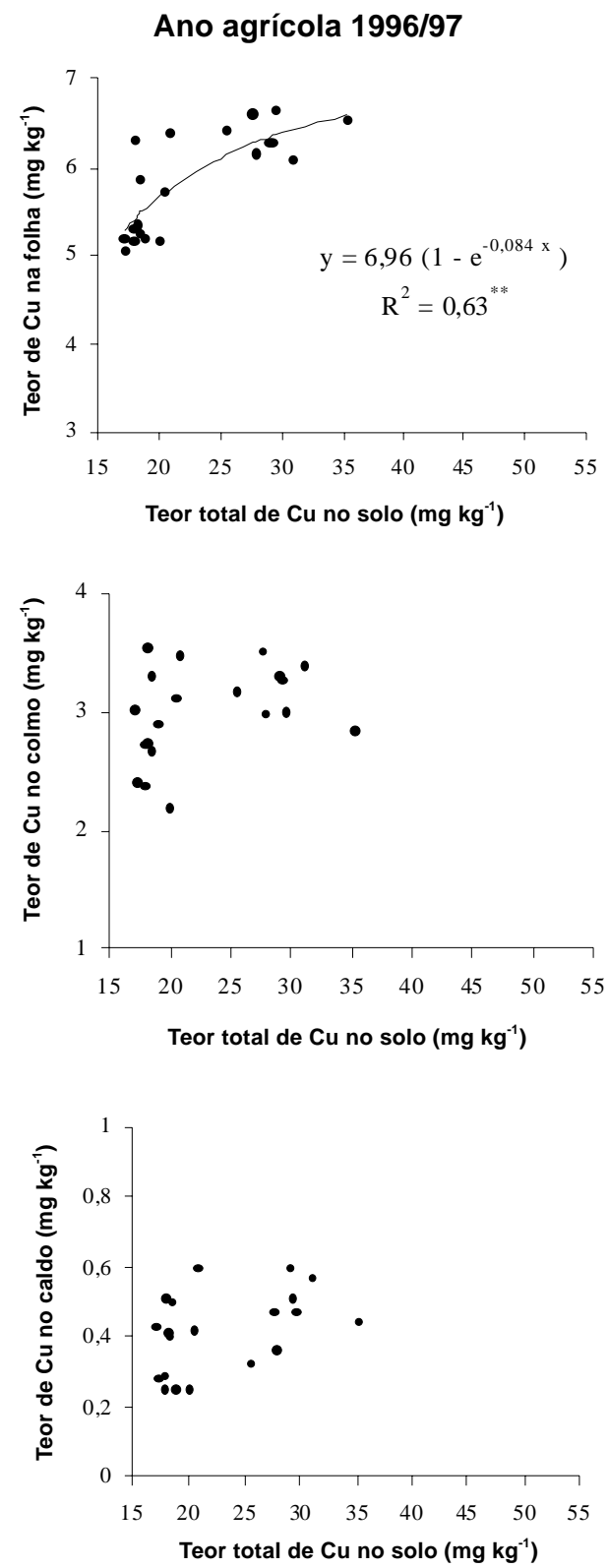

Anjos (1999), trabalhando com Latossolo Vermelho-Amarelo e Latossolo Roxo tratados com 388 $\mathrm{mg} \mathrm{ha}^{-1}$ (base seca) de lodo de esgoto proveniente da ETE-Barueri, verificou que os teores de $\mathrm{Cd}$ e $\mathrm{Pb}$ avaliados pelos extratores DTPA-TEA, $\mathrm{HCl} 0,1 \mathrm{~mol} \mathrm{~L}^{-1} \mathrm{e}$ Mehlich-3, também estiveram abaixo dos limites de determinação empregados no presente trabalho. Para o $\mathrm{Cr}$, o autor observou que os extratores $\mathrm{HCl} 0,1 \mathrm{~mol} \mathrm{~L}^{-1} \mathrm{e}$ Mehlich-3 foram capazes de extrair respectivamente, 9 e $3 \%$ do total adicionado através do resíduo no LV, ao passo que para o LR, somente a solução de Mehlich-3 extraiu $\mathrm{Cr}$, aproximadamente $2 \%$ do total adicionado. Não foi possível avaliar a eficiência dos extratores na previsão da fitodisponibilidade desses elementos, já que eles não foram detectados nas partes das plantas de milho.
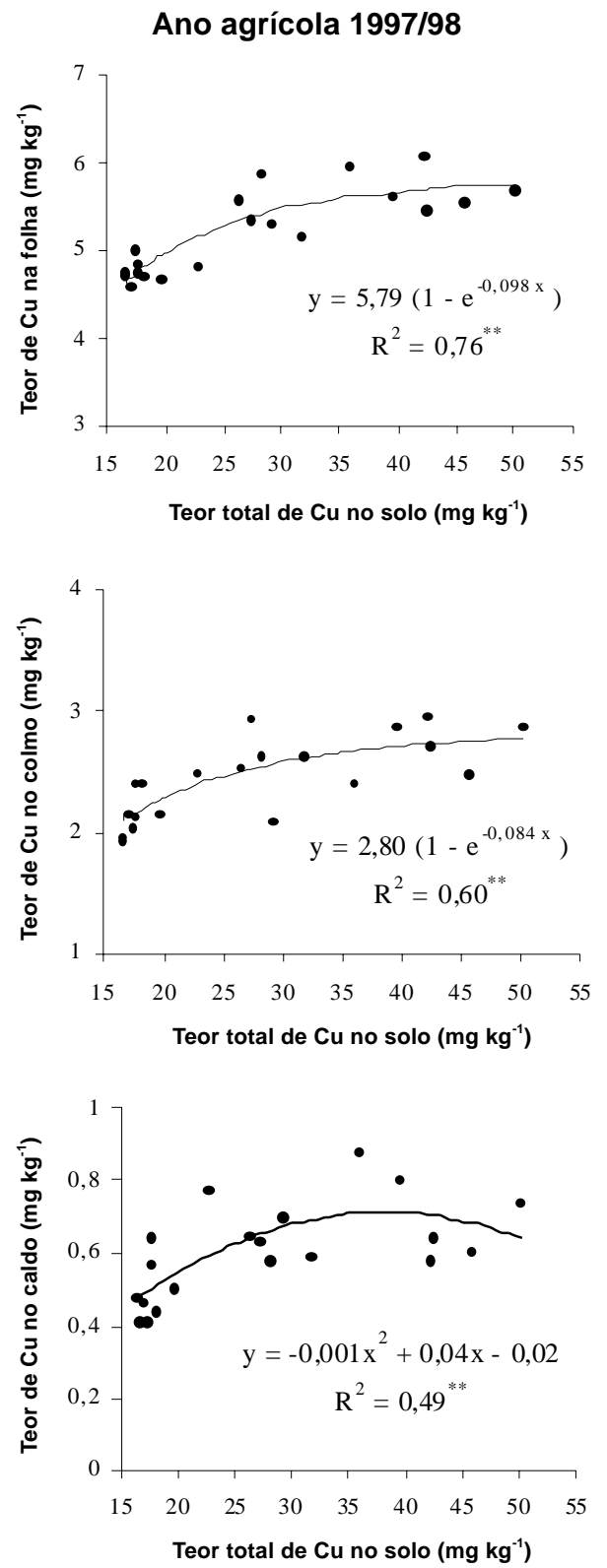

Figura 1 - Relações entre teores de cobre nas amostras de folha, colmo e caldo da cana-de-açúcar e teores totais determinados no solo. ("Modelo ajustado significativo a $\mathrm{P} \leq 0,01$ pelo teste $\mathrm{F}$ ) 
Na TABELA 5 são apresentados os teores de $\mathrm{Cu}$, $\mathrm{Ni}$ e $\mathrm{Zn}$ avaliados pelas soluções extratoras nos anos agrícolas 1996/97 e 1997/98. Considerando-se as quantidades aplicadas acumuladas desses metais no solo ao final do segundo ano agrícola (TABELA 4), é possível estimar que a extração média de $\mathrm{Cu}$, nos tratamentos $\mathrm{La}$, Lb e Lc foi de 17, 24 e 31\% respectivamente para os extratores DTPA-TEA, $\mathrm{HCl} \mathrm{0,1} \mathrm{mol} \mathrm{L}^{-1}$ e Mehlich-3; para o $\mathrm{Ni}$ tais valores foram de 8,28 e $23 \%$ e, para o $\mathrm{Zn}, 13,33$ e $35 \%$. Dessa forma, com relação a capacidade de extração dos métodos, verifica-se que aqueles que empregaram soluções ácidas ( $\mathrm{HCl} 0,1 \mathrm{~mol} \mathrm{~L}^{-1}$ e Mehlich-3) extraíram quantidades maiores que DTPA-TEA. Esses resultados, de acordo com Abreu et al. (1995) são, até certo ponto, esperados, já que os ácidos dissolvem parcialmente diversas estruturas que contêm os metais pesados.

Ano agrícola 1996/97

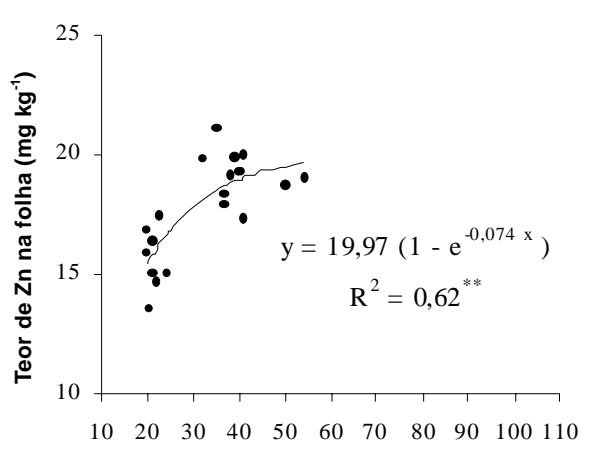

Teor total de $\mathrm{Zn}$ no solo $\left(\mathrm{mg} \mathrm{kg}^{-1}\right)$
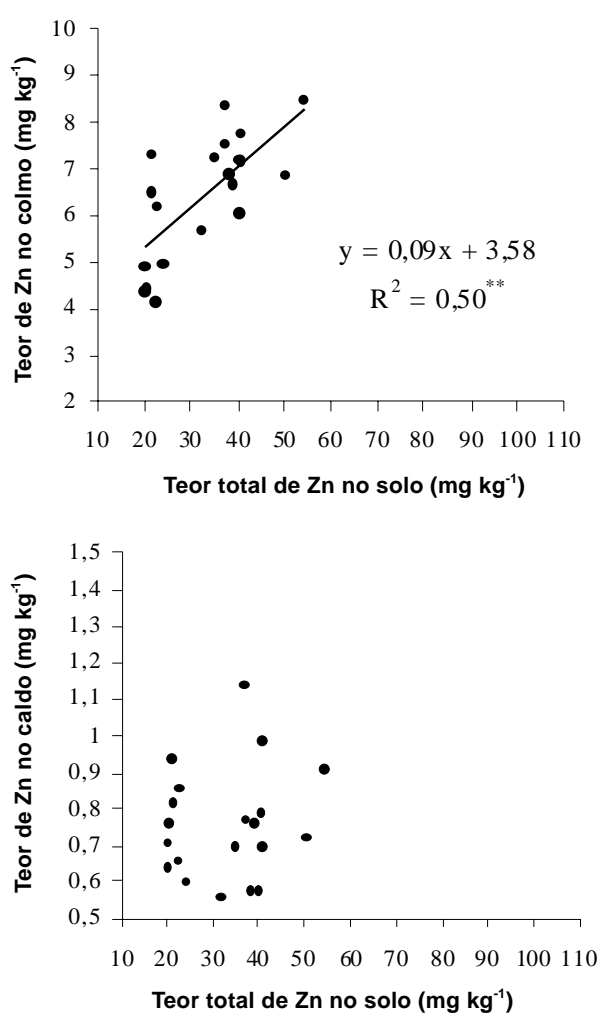

Dentre as soluções ácidas, a de Mehlich-3 apresentou a maior capacidade de extração para os metais $\mathrm{Cu}$ e $\mathrm{Zn}$ enquanto que, $\mathrm{HCl} \mathrm{0,1} \mathrm{mol} \mathrm{L}^{-1}$ foi superior na extração do Ni. Assim, considerando-se que a solução de Mehlich-3 é composta, além dos ácidos acético e nítrico, pelo complexante EDTA, é possível inferir que para os metais $\mathrm{Cu}$ e $\mathrm{Zn}$, o diferencial encontrado em relação ao $\mathrm{HCl} 0,1 \mathrm{~mol} \mathrm{~L}^{-1}$ pode ter sido devido a significativa presença desses elementos na fração orgânica do solo. Já para o Ni esta fração teria sido menos representativa.

As quantidades removidas de Cu e Zn pelas várias soluções extratoras, nos dois anos agrícolas, foram crescentes em função das doses de lodo de esgoto. Para o Ni este comportamento foi evidente apenas no segundo ano agrícola. De maneira geral, as quantidades extraídas
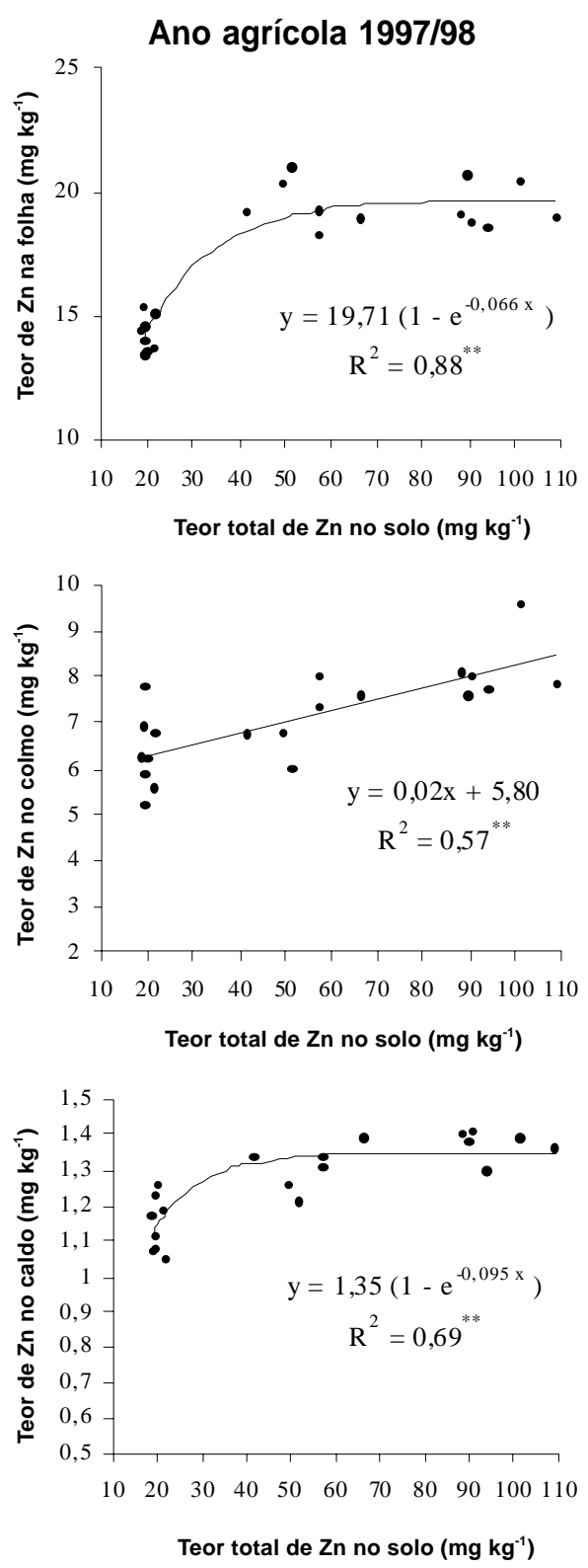

Figura 2 - Relações entre teores de zinco nas amostras de folha, colmo e caldo da cana-de-açúcar e teores totais determinados no solo. ("Modelo ajustado significativo a $\mathrm{P} \leq 0,01$ pelo teste $\mathrm{F}$ ) 
TABELA 5 - Teores de $\mathrm{Cu}, \mathrm{Ni}$ e $\mathrm{Zn}$ avaliados no solo pelos extratores DTPA-TEA, HCl 0,1 mol L-1 e Mehlich-3, nos anos agrícolas 1996/97 e 1997/98.

\begin{tabular}{|c|c|c|c|c|c|c|c|}
\hline \multirow{2}{*}{$\begin{array}{l}\text { Ano } \\
\text { Agrícola }\end{array}$} & \multirow[t]{2}{*}{ Extrator } & \multicolumn{4}{|c|}{ Dose de lodo de esgoto $\left(\mathrm{mg} \mathrm{ha}^{-1}\right)$} & \multicolumn{2}{|c|}{ Termo de Regressão $\left(R^{2}\right)$} \\
\hline & & 0 & $33(34)$ & $66(74)$ & $99(110)$ & Linear & Quadrático \\
\hline \multicolumn{8}{|c|}{ - Cobre $\left(\mathrm{mg} \mathrm{kg}^{-1}\right)$ - } \\
\hline $1996 / 97$ & DTPA-TEA & 0,70 & 2,97 & 3,86 & 3,86 & $0,80^{* *}$ & $0,99 *$ \\
\hline $1997 / 98$ & DTPA-TEA & 0,85 & 3,67 & 6,64 & 10,70 & $0,99^{* *}$ & ns \\
\hline $1996 / 97$ & $\mathrm{HCl} 0,1 \mathrm{~mol} \mathrm{~L}^{-1}$ & 0,90 & 5,23 & 5,35 & 6,64 & $0,80^{* *}$ & ns \\
\hline $1997 / 98$ & $\mathrm{HCl} \mathrm{0,1} \mathrm{mol} \mathrm{L}^{-1}$ & 0,98 & 5,43 & 10,39 & 11,66 & $0,96^{* *}$ & ns \\
\hline 1996/97 & Mehlich 3 & 1,22 & 6,05 & 8,48 & 7,70 & $0,75^{* *}$ & ns \\
\hline $1997 / 98$ & Mehlich 3 & 1,17 & 7,25 & 10,35 & 17,33 & $0,98^{\star *}$ & ns \\
\hline \multicolumn{8}{|c|}{ Níquel $\left(\mathrm{mg} \mathrm{kg}^{-1}\right)$--- } \\
\hline $1996 / 97$ & DTPA-TEA & n.d. ${ }^{2}$ & 0,47 & 0,70 & 0,65 & ns & - \\
\hline $1997 / 98$ & DTPA-TEA & n.d. & 0,51 & 1,11 & 1,90 & $0,99^{* *}$ & - \\
\hline $1996 / 97$ & $\mathrm{HCl} 0,1 \mathrm{~mol} \mathrm{~L}-1$ & n.d. & 1,41 & 2,33 & 1,98 & ns & - \\
\hline $1997 / 98$ & $\mathrm{HCl} 0,1 \mathrm{~mol} \mathrm{~L}^{-1}$ & n.d. & 1,78 & 4,09 & 5,93 & $0,99^{* *}$ & - \\
\hline $1996 / 97$ & Mehlich 3 & n.d. & 1,02 & 2,03 & 2,23 & ns & - \\
\hline $1997 / 98$ & Mehlich 3 & n.d. & 1,50 & 3,68 & 4,45 & $0,78^{*}$ & - \\
\hline \multicolumn{8}{|c|}{ Zinco $\left(\mathrm{mg} \mathrm{kg}^{-1}\right)$-- } \\
\hline $1996 / 97$ & DTPA-TEA & 0,62 & 4,76 & 6,34 & 6,71 & $0,84^{\star \star}$ & ns \\
\hline $1997 / 98$ & DTPA-TEA & 0,75 & 6,43 & 10,27 & 19,12 & $0,97^{\star *}$ & ns \\
\hline $1996 / 97$ & $\mathrm{HCl} 0,1 \mathrm{~mol} \mathrm{~L}^{-1}$ & 0,94 & 12,23 & 11,23 & 13,35 & $0,67^{\star *}$ & $0,88^{* *}$ \\
\hline $1997 / 98$ & $\mathrm{HCl} 0,1 \mathrm{~mol} \mathrm{~L}^{-1}$ & 0,90 & 14,09 & 24,86 & 52,05 & $0,95^{\star *}$ & ns \\
\hline $1996 / 97$ & Mehlich 3 & 1,25 & 12,28 & 13,95 & 16,90 & $0,84^{* *}$ & 0,96 ** \\
\hline $1997 / 98$ & Mehlich 3 & 1,23 & 16,85 & 30,95 & 44,95 & $0,99^{* *}$ & ns \\
\hline
\end{tabular}

${ }^{1}$ Doses entre parênteses referem-se ao ano agrícola 1997/98; ${ }^{2}$ n.d. - não detectado, valor abaixo do limite de determinação do método analítico, 0,20, 0,50 e 1,00 mg kg ${ }^{-1}$ na amostra, respectivamente para os extratores DTPA-TEA, HCl 0,1 mol L-1 e Mehlich 3; *, **, ${ }^{\text {ns }}$ Indicam respectivamente, que os termos de regressão linear ou quadrática foram significativos a $P \leq 0,05, P \leq 0,01$ ou não significativo pelo teste $F$.

ocorreram na seguinte ordem: $\mathrm{Zn}>\mathrm{Cu}>\mathrm{Ni}$; resultados que refletem os teores presentes no lodo de esgoto e as taxas em que foram aplicados no solo. Tais resultados também sugerem que a fitodisponibilidade desses elementos seria supostamente crescente em função da taxa de aplicação do lodo de esgoto. Comportamentos semelhantes foram observados por Rappaport et al. (1988), King \& Hajjar (1990) e Roca \& Pomares (1991), em solos tratados com lodo de esgoto, respectivamente para os extratores DTPA-TEA, DTPA-TEA e Mehlich-3 e DTPA-TEA, $\mathrm{HCl}$ 0,1 $m o l L^{-1} e$ "água régia".

Embora tenham sido observadas diferenças na capacidade de extração das soluções utilizadas, verificase de maneira geral, correlações significativas entre todos os métodos, incluindo a "água régia", para os elementos Cu e Zn (TABELA 6). Exceção deve ser feita apenas para o ano agrícola 1996/97, quando foram considerados os teores avaliados pela "água régia" nos tratamentos La, Lb e Lc. Para o Ni, as correlações não foram realizadas com o referido extrator, tendo em vista que seus teores estiveram abaixo do limite de determinação do método analítico. Porém, para La, Lb e Lc, houve correlações entre os teores de Ni extraídos por DTPA-TEA, $\mathrm{HCl} 0,1 \mathrm{~mol} \mathrm{~L}^{-1}$ e Mehlich-3. Verifica-se portanto, que todas as soluções empregadas fornecem indicações semelhantes para $\mathrm{Cu}$ e $\mathrm{Zn}$, enquanto que para $\mathrm{Ni}$, esta inferência não poderia ser feita apenas para a "água régia". Esses resultados vão de encontro àqueles obtidos por Roca \& Pomares (1991), os quais encontraram correlações significativas entre os teores de

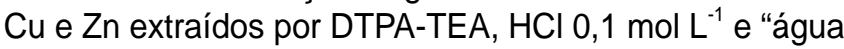
régia". Para o Ni, tais correlações não foram obtidas para a "água régia". Abreu et al. (1995) observaram correlações significativas entre os teores de Ni extraídos por DTPA-TEA e Mehlich-3.

A eficiência dos extratores químicos na previsão da disponibilidade dos metais pesados às plantas de cana-de-açúcar foi avaliada apenas para $\mathrm{Cu}$ e $\mathrm{Zn}$ tendo em vista que o $\mathrm{Ni}$ não foi detectado nas amostras de plantas. Dessa forma, são apresentados na TABELA 7 os coeficientes de correlação linear obtidos entre as concentrações desses metais nas amostras de plantas e no solo, considerando todos os tratamentos empregados.

Verifica-se de maneira geral, que todas as soluções extratoras foram eficientes na avaliação da disponibilidade de $\mathrm{Cu}$ e $\mathrm{Zn}$, utilizando-se como índice os teores presentes na folha " +1 ", no colmo desfibrado e no caldo. Exceções são feitas apenas no primeiro ano agrícola, entre os teores de $\mathrm{Cu}$ no colmo e caldo e àqueles extraídos do solo por "água régia" e entre os teores de $\mathrm{Zn}$ no caldo e àqueles extraídos do solo, por todos os extratores químicos. Neste ano porém, ressaltase que a cana-de-açúcar (cana-planta) foi colhida com 11 meses e apresentou um crescimento prejudicado e diferenciado em função dos tratamentos (Oliveira, 2000). 
Além disso, os aumentos dos teores desses elementos no solo não proporcionaram acréscimos nos teores presentes no colmo e no caldo.

Resultados satisfatórios para DTPA-TEA e Mehlich-3, na previsão da disponibilidade de Cu e Zn para plantas cultivadas em solos acrescidos de lodo de esgoto, têm sido encontrados por diversos autores (Singh \& Narwal, 1984; King \& Hajjar, 1990; Mulchi et al., 1991, Anjos, 1999). Porém, existem grandes variações no comportamento dos extratores em função das espécies vegetais consideradas (Roca \& Pomares, 1991).

Analisando-se as relações entre as quantidades totais de $\mathrm{Cu}$ e $\mathrm{Zn}$ recuperadas do solo, nos dois anos agrícolas, e seus teores nas várias amostras de plantas (Figuras 1 e 2) e considerando-se que houve correlações significativas entre os chamados teores totais (extraídos por "água régia") e aqueles avaliados pelos demais extratores químicos, é importante notar que, na maioria dos casos em que foram verificados efeitos significativos

TABELA 6 - Coeficientes de correlação linear simples para os teores avaliados de Cu, Ni e Zn entre os extratores água régia, DTPA-TEA, HCl 0,1 mol L-1 e Mehlich-3 (M-3), nos anos agrícolas de 1996/97 e 1997/98.

\begin{tabular}{|c|c|c|c|c|c|c|c|c|c|}
\hline \multirow[t]{2}{*}{ Extrator } & \multicolumn{3}{|c|}{ Cobre } & \multicolumn{3}{|c|}{ Níquel } & \multicolumn{3}{|c|}{ Zinco } \\
\hline & DTPA & $\mathrm{HCl}$ & $\mathrm{M}-3$ & DTPA & $\mathrm{HCl}$ & M-3 & DTPA & $\mathrm{HCl}$ & $\mathrm{M}-3$ \\
\hline \multicolumn{10}{|c|}{ Ano agrícola 1996/97 (considerando os tratamentos T, AM, La, Lb e Lc) } \\
\hline água régia & $0,75^{* *}$ & $0,71^{* *}$ & $0,68^{* *}$ & - & - & - & $0,88^{* \star}$ & $0,86^{\star *}$ & $0,90^{\star \star}$ \\
\hline DTPA & - & $0,97^{\star \star}$ & $0,97^{\star *}$ & - & - & - & - & $0,93^{* \star}$ & $0,93^{\star \star}$ \\
\hline $\mathrm{HCl}$ & - & - & $0,93^{* *}$ & - & - & - & - & - & $0,96^{* \star}$ \\
\hline \multicolumn{10}{|c|}{ Ano agrícola 1996/97 (considerando os tratamentos La, Lb e Lc) } \\
\hline água régia & $0,46^{\text {ns }}$ & $0,33^{\text {rs }}$ & $0,35^{\text {ns }}$ & - & - & - & $0,48^{\text {rs }}$ & $0,10^{\text {ns }}$ & $0,36^{\text {ns }}$ \\
\hline DTPA & - & $0,86^{* \star}$ & $0,95^{\star *}$ & - & $0,89^{* \star}$ & $0,84^{* \star}$ & - & 0,70 * & 0,70 * \\
\hline $\mathrm{HCl}$ & - & - & $0,80^{* *}$ & - & - & $0,85^{\star *}$ & - & - & $0,47^{\text {ns }}$ \\
\hline \multicolumn{10}{|c|}{ Ano agrícola 1997/98 (considerando os tratamentos T, AM, La, Lb e Lc) } \\
\hline água régia & $0,98^{* *}$ & $0,91^{* *}$ & $0,95^{\star *}$ & - & - & - & $0,95^{\star \star}$ & $0,94^{\star *}$ & $0,98^{* \star}$ \\
\hline DTPA & - & $0,90^{\star *}$ & $0,96^{* *}$ & - & - & - & - & $0,98^{* \star}$ & $0,96^{* \star}$ \\
\hline $\mathrm{HCl}$ & - & - & $0,91^{\star \star}$ & - & - & - & - & - & $0,97^{\star \star}$ \\
\hline \multicolumn{10}{|c|}{ Ano agrícola 1997/98 (considerando os tratamentos La, Lb e Lc) } \\
\hline água régia & $0,96^{* *}$ & $0,75^{\star \star}$ & $0,85^{\star *}$ & - & - & - & $0,88^{\star *}$ & $0,87^{\star \star}$ & $0,93^{* *}$ \\
\hline DTPA & - & $0,75^{\star \star}$ & $0,91^{\text {**}}$ & - & $0,98^{\star \star}$ & $0,87^{\star \star}$ & - & $0,96^{* \star}$ & $0,91^{* *}$ \\
\hline $\mathrm{HCl}$ & - & - & $0,71^{* \star}$ & - & - & $0,92^{* \star}$ & - & - & $0,95^{\star \star}$ \\
\hline
\end{tabular}

*, **, ns Indicam respectivamente, que as correlações foram significativas a $P \leq 0,05, P \leq 0,01$ ou não significativas pelo teste $t$.

TABELA 7 - Correlações lineares entre a concentração de cobre e zinco nas plantas de cana-de-açúcar e os teores avaliados no solo pelos vários extratores químicos, considerando todos os tratamentos.

\begin{tabular}{|c|c|c|c|c|}
\hline Metal pesado & Água-régia & DTPA-TEA & $\mathrm{HCl} 0,1 \mathrm{~mol} \mathrm{~L}^{-1}$ & Mehlich-3 \\
\hline & \multirow{2}{*}{\multicolumn{4}{|c|}{$\begin{array}{c}\text { Ano agrícola 1996/97 } \\
\text { Folha "+1" }\end{array}$}} \\
\hline & & & & \\
\hline Cobre & $0,73^{* *}$ & $0,83^{* \star}$ & $0,84^{\star \star}$ & $0,74^{\star *}$ \\
\hline \multirow[t]{2}{*}{ Zinco } & $0,69^{\star *}$ & $0,65^{\star *}$ & $0,78^{\star *}$ & $0,77^{\star *}$ \\
\hline & \multicolumn{4}{|c|}{ Colmo } \\
\hline Cobre & $0,38^{\text {ns }}$ & $0,64^{* *}$ & $0,65^{\star *}$ & $0,60^{* *}$ \\
\hline \multirow[t]{2}{*}{ Zinco } & $0,69^{* *}$ & $0,64^{* *}$ & $0,63^{* *}$ & $0,59^{* *}$ \\
\hline & \multicolumn{4}{|c|}{ Caldo } \\
\hline Cobre & $0,43^{\text {ns }}$ & $0,67^{\star \star}$ & $0,67^{\star *}$ & $0,69^{* *}$ \\
\hline \multirow[t]{3}{*}{ Zinco } & $0,14^{\mathrm{ns}}$ & $0,25^{\text {ns }}$ & $0,22 \mathrm{~ns}$ & $0,08^{\text {ns }}$ \\
\hline & \multicolumn{4}{|c|}{ Ano agrícola 1997/98 } \\
\hline & \multicolumn{4}{|c|}{ Folha "+1" } \\
\hline Cobre & $0,84^{\star *}$ & $0,80^{* *}$ & $0,84^{* *}$ & $0,83^{\star *}$ \\
\hline \multirow[t]{2}{*}{ Zinco } & $0,79^{* *}$ & $0,75^{\star \star}$ & $0,73^{\star *}$ & $0,78^{\star *}$ \\
\hline & \multicolumn{4}{|c|}{ Colmo } \\
\hline Cobre & $0,73^{* *}$ & $0,68^{\star *}$ & $0,66^{\star *}$ & $0,66^{\star *}$ \\
\hline \multirow[t]{2}{*}{ Zinco } & $0,75^{\star \star}$ & $0,78^{\star *}$ & $0,74^{\star *}$ & $0,78^{* *}$ \\
\hline & \multicolumn{4}{|c|}{ Caldo } \\
\hline Cobre & $0,59^{* *}$ & $0,62^{\star *}$ & $0,65^{\star \star}$ & $0,74^{\star \star}$ \\
\hline Zinco & $0,82^{* *}$ & $0,80^{* *}$ & $0,77^{\star *}$ & $0,83^{* *}$ \\
\hline
\end{tabular}

**, ns Indicam respectivamente, que as correlações foram significativas a $\mathrm{P} \leq 0,01$ e não significativas pelo teste t. 
dos teores de metais do solo sobre a concentração nas amostras de plantas, foram definidos dois grupos distintos de concentrações nas plantas; o primeiro referente aos tratamentos AM e T e o segundo, referente aos tratamentos $\mathrm{La}$, Lb e Lc. Este fato evidenciou em alguns casos, a não variação entre os teores de $\mathrm{Cu}$ e $\mathrm{Zn}$ nas plantas cultivadas nos tratamentos $\mathrm{La}$, Lb e Lc, o que poderia tornar tendenciosa a validação da eficiência dos extratores químicos testados.

Diante disto, procederam-se correlações entre os teores recuperados do solo, somente nos tratamentos La, $\mathrm{Lb}$ e $\mathrm{Lc}$ e os teores presentes nas amostras de plantas cultivadas nestes tratamentos (TABELA 8).

Neste caso, todos os extratores foram ineficientes para avaliar a disponibilidade de Cu através das amostras de folhas " +1 ", colmo e caldo das plantas de cana-de-açúcar. A não ocorrência de correlações significativas foi devida a falta de resposta das plantas aos acréscimos de $\mathrm{Cu}$ no solo proporcionados pela aplicação de lodo de esgoto, enquanto que os extratores químicos extraíram quantidades lineares e crescentes em função das doses. Em situação semelhante, Rappaport et al. (1988) verificaram que a ineficiência do extrator DTPA-TEA em prever a disponibilidade de Cd, $\mathrm{Cu}$, Ni e $\mathrm{Zn}$ foi devida ao fato de que doses de lodo de esgoto $\left(0,42,84,126,168\right.$ e $210 \mathrm{mg} \mathrm{ha}^{-1}$ - base seca) praticamente não promoveram aumentos na absorção, por plantas de milho, desses metais pesados.

Para o $\mathrm{Zn}$, a utilização de folhas " 1 " não foi um bom índice na avaliação de sua disponibilidade para todas as soluções extratoras. Certamente este fato esteve relacionado ao comportamento assintótico observado para as concentrações do elemento nestas amostras. Por outro lado, quando foram consideradas as amostras de colmo e caldo, no ano agrícola 1997/98, foram obtidas correlações significativas e positivas com todos os extratores, destacando-se as soluções de Mehlich-3 para o colmo e DTPA-TEA e Mehlich-3 para o caldo. As correlações com as amostras de colmo apresentaram, de forma geral, coeficientes maiores do que aqueles encontrados com as amostras de caldo, o que pode ser explicado pelo comportamento linear crescente apresentado pelo elemento no colmo, em função dos acréscimos do metal no solo.

Bidwell \& Dowdy (1987) trabalhando com um solo siltoso tratado com lodo de esgoto $(0,60,120$ e 180 $\mathrm{mg} \mathrm{ha}^{-1}$ - base seca) observaram que as elevadas correlações obtidas entre os teores de $\mathrm{Cd}$ e $\mathrm{Zn}$ avaliados por DTPA-TEA e em plantas de milho deveriam ser vistas com cautela. Eles verificaram que para níveis constantes de metais avaliados no solo, houve diminuição dos teores nas plantas cultivadas seqüencialmente.

Todos os resultados obtidos para os extratores químicos devem ser vistos com reservas uma vez que, na hipótese de interrupção nas aplicações de lodo, ficam dúvidas a respeito da disponibilidade desses elementos a medida em que a carga orgânica do resíduo for se degradando e a acidez do solo aumentando. Neste contexto, insere-se também o comportamento característico de cada espécie vegetal, já que existem trabalhos na literatura que demonstram que plantas cultivadas em solos cuja contaminação por metais pesados é devida a disposição de resíduos orgânicos, nem sempre absorvem esses elementos de forma crescente e linear em função das quantidades aplicadas (Corey et al., 1987; Barbarick et al., 1995; Logan et al., 1997).

TABELA 8 - Correlações lineares entre a concentração de cobre e zinco nas plantas de cana-de-açúcar e os teores avaliados no solo pelos vários extratores químicos, considerando apenas os tratamentos La, Lb e Lc.

\begin{tabular}{|c|c|c|c|c|}
\hline Metal pesado & água-régia & DTPA-TEA & $\mathrm{HCl} 0,1 \mathrm{~mol} \mathrm{~L}^{-1}$ & Mehlich-3 \\
\hline & \multicolumn{4}{|c|}{ Ano agrícola 1996/97 } \\
\hline & \multicolumn{4}{|c|}{ Folha "+1" } \\
\hline Cobre & $0,49^{\text {ns }}$ & $0,10^{\text {ns }}$ & $0,06^{\text {ns }}$ & $0,04^{\text {ns }}$ \\
\hline \multirow[t]{2}{*}{ Zinco } & $-0,40^{\text {ns }}$ & $-0,50^{\text {ns }}$ & $-0,26^{\text {ns }}$ & $-0,13^{\text {ns }}$ \\
\hline & \multicolumn{4}{|c|}{ Colmo } \\
\hline Cobre & $-0,52^{\text {ns }}$ & $-0,25^{\mathrm{ns}}$ & $-0,29^{\text {ns }}$ & $-0,12^{\text {ns }}$ \\
\hline \multirow[t]{2}{*}{ Zinco } & $0,45^{\text {ns }}$ & $0,31^{\text {ns }}$ & $0,15^{\text {ns }}$ & $-0,13^{\text {ns }}$ \\
\hline & \multicolumn{4}{|c|}{ Caldo } \\
\hline Cobre & $-0,06^{\text {ns }}$ & $0,31^{\text {ns }}$ & $0,29^{\text {ns }}$ & $0,45^{\text {ns }}$ \\
\hline \multirow[t]{3}{*}{ Zinco } & $0,24^{\text {rs }}$ & $0,47^{\text {ns }}$ & $0,66^{\star}$ & $0,11^{\mathrm{rs}}$ \\
\hline & \multicolumn{4}{|c|}{ Ano agrícola 1997/98 } \\
\hline & \multicolumn{4}{|c|}{ Folha "+1" } \\
\hline Cobre & $0,56^{\text {ns }}$ & $0,50^{\text {ns }}$ & $0,50^{\text {ns }}$ & $0,48^{\text {ns }}$ \\
\hline \multirow[t]{2}{*}{ Zinco } & $-0,12^{\text {ns }}$ & $0,06^{\text {ns }}$ & $0,08^{\text {ns }}$ & $-0,16^{\text {ns }}$ \\
\hline & \multicolumn{4}{|c|}{ Colmo } \\
\hline Cobre & $0,37^{\text {ns }}$ & $0,29^{\text {ns }}$ & $0,13^{\text {ns }}$ & $0,13^{\text {ns }}$ \\
\hline \multirow[t]{2}{*}{ Zinco } & $0,71^{\star \star}$ & $0,76^{\star \star}$ & $0,68^{*}$ & $0,80^{\star \star}$ \\
\hline & \multicolumn{4}{|c|}{ Caldo } \\
\hline Cobre & $0,02^{\text {ns }}$ & $0,16^{\text {ns }}$ & $0,10^{\text {ns }}$ & $0,42^{\text {rs }}$ \\
\hline Zinco & $0,57^{*}$ & $0,65^{\star}$ & $0,59^{*}$ & $0,63^{*}$ \\
\hline
\end{tabular}

Scientia Agricola, v.58, n.3, p.581-593, jul./set. 2001 


\section{AGRADECIMENTOS}

À Fundação de Amparo à Pesquisa do Estado de São Paulo pelo financiamento do projeto que deu origem a este trabalho, à Estação Experimental do IAC de Piracicaba, SP, pelo apoio e concessão de uso da área experimental e aos técnicos de laboratório Lenita M. C. Pacheco e Oliveira e Carlos Rubini Junior, do Depto. de Ciências Exatas da USP/ESALQ, pela colaboração nos procedimentos analíticos.

\section{REFERÊNCIAS BIBLIOGRÁFICAS}

ABREU, C.A.; ABREU, M.F.; RAIJ, B. van.; SANTOS, W.R. Comparação de métodos de análise para avaliar a disponibilidade de metais pesados em solos. Revista Brasileira de Ciência do Solo, v.19, p.463-468, 1995.

ANJOS, A.R.M. dos. Lixiviação de espécies químicas em latossolos sucessivamente tratados com biossólido e disponibilidade de metais pesados para plantas de milho. Piracicaba, 1999. 191p. Tese (Doutorado) - Escola Superior de Agricultura "Luiz de Queiroz", Universidade de São Paulo.

BARBARICK, K.A.; IPPOLITO, J.A.; WESTFALL, D.G. Biosolids effect on phosphorus, copper, zinc, nickel, and molybdenum concentrations in dryland wheat. Journal of Environmental Quality, v.24, p.608-611, 1995.

BAXTER, J.C.; AGUILAR, M.; BROWN, K. Heavy metals and persistent organics at a sewage sludge disposal site. Journal of Environmental Quality, v.12, p.311-316, 1983.

BIDWELL, A.M.; DOWDY, R.H. Cadmium and zinc availabilty to corn following termination of sewage sludge applications. Journal of Environmental Quality, v.16, p.438-442, 1987.

CHANG, A.C.; HINESLY, T.D.; BATES, T.E.; DONER, H.E.; DOWDY, R.H.; RYAN, J.A. Effects of long term sludge application on accumulation of trace elements by crops. In: PAGE, A.L.; LOGAN, T.J.; RYAN, J.A. (Ed.) Land application of sludge: food chain implications. Chelsea: Lewis Publishers, 1987. cap.4, p.53-66.

CHANG, A.C.; HYUN, H.; PAGE, A.L. Cadmium uptake for swiss chard grown on composted sewage sludge treated field plots: plateau or time bomb? Journal of Environmental Quality, v.26, p.11-19, 1997.

CLEMENTS, H.F. Sugarcane crop logging and crop control: principles and practices. Hawaii: University Press of Hawaii, 1980. 520p.

COMPANHIA DE TECNOLOGIA DE SANEAMENTO AMBIENTAL. Aplicação de lodos de sistemas de tratamento biológico em áreas agrícolas - critérios para projeto e operação: manual técnico, São Paulo: CETESB, 1999, 32p.

COREY, R.B.; KING, L.D.; LUE-HING, C.; FANNING, D.S.; STREET, J.J.; WALKER, J.M. Effects of sludge properties on accumulation of trace elements by crops. In: PAGE, A.L.; LOGAN, T.J.; RYAN, J.A. (Ed.) Land application of sludge: food chain implications. Chelsea: Lewis Publishers, 1987. cap.3, p.25-51.

CUNNINGHAM, I.D.; KEENEY, D.R.; RYAN, J.A. Yield and metal composition of crop and rye grown on sewage sludge amended soil. Journal of Environmental Quality, v.4, p.448-454, 1975.

DANG, Y.P.; CHHABRA, R.; VERMA, K.S. Effect of Cd, Ni, Pb and $\mathrm{Zn}$ on growth and chemical composition of onion and fenugreek. Communications in Soil Science and Plant Analysis, v.21, p.717-735, 1990
EATON, A.D.; CLESCERI, L.S.; GRENNBERG, A.E. Standard methods for the examination of water and wastewater. 19.ed. Washington: APHA/AWWA/WEF, 1995. 1082p.

HALL, J.E. Standardising and the management of biosolids the international experience. In: SEMINÁRIO SOBRE GERENCIAMENTO DE BIOSSÓLIDOS DO MERCOSUL. 1., Curitiba, 1998. Anais. Curitiba: SANEPAR/ABES, 1998. p.113-122.

KELLER, C.; VÉDY, J.C. Distribution of copper and cadmium fractions in two forest soils. Journal of Environmental Quality, v.23, p.987-999, 1994.

KIEKENS, L.; COTTENIE, A. Principles of investigation on the mobility and plant uptake of heavy metals. In: LESCHBER, R.; DAVIES, R.D.; L'HERMITE, P. (Ed.) Chemical methods for assessing bioavailability metals in sludge and soils. London: Elsevier, 1985. p.32-41.

KING, L.D.; HAJJAR, L.M. The residual effect of sewage sludge on heavy metal content of tobacco and peanut. Journal of Environmental Quality, v.19, p.738-748, 1990.

KING, L.D.; MORRIS, H.D. Land disposal of liquid sewage sludge II. The effect on soil $\mathrm{pH}$, manganese, zinc, and growth and chemical composition of rye (Cecale cereale L.). Journal of Environmental Quality, v.19, p.425-429, 1972.

LESCHBER, R.; DAVIES, R.D.; L'HERMITE, P. Chemical methods for assessing bioavailability metals in sludge and soils. London: Elsevier, 1985. 96p.

LINDSAY, W.L.; NORVELL, W.A. Development of a DTPA test for zinc, iron, manganese and copper. Soil Science Society of America Journal, v.42, p.421-428, 1978.

LOGAN, T.J.; CHANEY, R.L. Nonlinear rate response and relative crop uptake of sludge cadmium for land application of sludge risk assessment. In: INTERNATIONAL CONFERENCE HEAVY METALS IN THE ENVIRONMENT, 6., Edinburgh, 1987. Proceedings. Edinburgh: CEP Consultants, 1987. p.387-388.

LOGAN, T.J.; LINDSAY, B.J.; GOINS, L.E.; RYAN, J.A. Field assessment of sludge metal bioavailability to crops: sludge rate response. Journal of Environmental Quality, v.26, p.534-550, 1997.

McBRIDE, M.B. Toxic metal accumulation from agricultural use of sludge: are USEPA regulations protective? Journal of Environmental Quality, v.24, p.5-18, 1995.

MACHADO, C.R. Incorporação de resíduos urbans e as propriedades físico-hídricas de um Latossolo VermelhoAmarelo. Piracicaba, 1999. 93p. Tese (Doutorado) - Escola Superior de Agricultura "Luiz de Queiroz", Universidade de São Paulo.

MARQUES, M.O. Incorporação de lodo de esgoto em solo cultivado com cana-de-açúcar. Jaboticabal, 1996. 111p. Tese (LivreDocência) - Faculdade de Ciências Agrárias e Veterinárias, Universidade Estadual Paulista "Júlio de Mesquita Filho".

MEHLICH, A. Mehlich 3 soil test extractant: a modification of Mehlich 2 extractant. Communications in Soil Science and Plant Analysis, v.15, p.1409-1416, 1984.

MULCHI, C.L.; ADAMU, C.A.; BELL, P.F.; CHANEY, R.L. Residual heavy metal concentrations in sludge-amended coastal plain soils: I. Comparison of extractants. Communications in Soil Science and Plant Analysis, v.22, p.919-941, 1991.

NIEUWENHUIZE, J.; POLEY-VOS, C.H.; AKKER, A.H.van den; DELFT, W.van. Comparison of microwave and conventional extraction techniques for the determination of metals in soil, sediment and sludge samples by atomic spectrometry. Analyst, v.116, p.347-351, 1991.

OLIVEIRA, F.C. Disposição de lodo de esgoto e composto de lixo urbano num Latossolo Vermelho-Amarelo cultivado com cana-de-açúcar. Piracicaba, 2000. 247p. Tese (Doutorado) Escola Superior de Agricultura “Luiz de Queiroz", Universidade de São Paulo. 
ORLANDO FILHO, J.; ZAMBELLO JR., E.; HAAG, H.P. Influência do solo na absorção de cobre pela cana-de-açúcar, variedade CB 41-76 em função da idade. In: CONGRESSO NACIONAL DA SOCIEDADE DE TÉCNICOS AÇÚCAREIROS DO BRASIL, 1., Maceió, 1979. Anais. Maceió, 1980a.

ORLANDO FILHO, J.; ZAMBELLO JR., E.; HAAG, H.P. Absorção e remoção de zinco pela cana-de-açúcar, variedade CB 4176, em três solos no Estado de São Paulo. Brasil Açúcareiro, v.96, p.21-30, 1980b.

PAGE, A.L.; LOGAN, T.J.; RYAN, J.A. Land application of sludge: food chain implications. Chelsea: Lewis Publishers, 1987. 168p.

RAPPAPORT, B.D.; MARTENS, D.C.; RENEAU JR, R.B.; SIMPSON, T.W. Metal availability in sludge-amended soils with elevated metal levels. Journal of Environmental Quality, v.17, p.42-47, 1988.

REED, S.T.; MARTENS, D.C. Copper and zinc. In: SPARKS, D.L. (Ed.) Methods of soil analysis: chemical methods. Madison: ASA, SSSA, 1996. cap.26, part.3, p.703-722.

ROCA, J.; POMARES, F. Prediction of available heavy metals by six chemical extractants in a sewage sludge-amended soil. Communications in Soil Science and Plant Analysis, v.22, p.2129-2136, 1991.

SETZER, J. Atlas climático e ecológico do Estado de São Paulo. São Paulo: Comissão Interestadual da Bacia ParanáUruguai, 1966. 61p.

SILVA, F.C. Uso agronômico de lodo de esgoto: efeitos em fertilidade do solo e qualidade da cana-de-açúcar. Piracicaba, 1995. 170p. Tese (Doutorado) - Escola Superior de Agricultura "Luiz de Queiroz", Universidade de São Paulo.
SINGH, B.R.; NARWAL, R.P. Plant availability of heavy metals in a sludge-treated soil: II. Metal extractability compared with plant metal uptake. Journal of Environmental Quality, v.13, p.344-349, 1984.

SOBRAL, F.A.; WEBER, H. Nutrição mineral da cana-de-açúcar (micronutrientes). In: ORLANDO FILHO, J. (Ed.) Nutrição e adubação da cana-de-açúcar no Brasil. Piracicaba: Planalsucar, 1983. cap.5, p.103-122.

SPIRONELLO, A.; RAIJ, B.van.; PENATTI, C.P.; CANTARELLA, H.; MORELLI, J.L.; ORLANDO FILHO, J.; LANDELL, M.G.A.; ROSSETO, R.; Cana-de-açúcar. In: RAIJ, B.van.; CANTARELLA, H.; QUAGGIO, J.A.; FURLANI, A.M.C. (Ed.) Recomendações de adubação e calagem para o Estado de São Paulo. Campinas: IAC, 1996. p.237-239.

UNITED STATES ENVIRONMENTAL PROTECTION AGENCY - USEPA. Title 40 CFR - Part 503. Final rules: Standards for the use or disposal of sewage sludge. Federal Register, v.58, p.9387-9415, 1993.

WALLACE, A.; WALLACE, G.A. A possible flaw in EPA's 1993 new sludge rule due heavy metal interactions. Communications in Soil Science and Plant Analysis, v.25, p.129-135, 1994.

$\overline{\text { Recebido em } 01} .06 .00$ 